\title{
Ação antibacteriana de Rosmarinus officinalis L. e Maytenus ilicifolia Mart. sobre bactérias orais
}

\author{
Antibacterial activity of Rosmarinus officinalis L. and Maytenus \\ ilicifolia Mart. on oral bacteria
}

\author{
Julio Cesar Campos Ferreira Filho* \\ Isabella Lima Arrais Ribeiro** \\ Julia Medeiros Martins ${ }^{* * *}$ \\ Lucas Pereira Borges ${ }^{* * *}$ \\ Ana Maria Gondim Valença $a^{* * *}$
}

\section{Resumo}

Objetivo: avaliar a atividade antibacteriana in vitro das tinturas hidroalcoólicas das folhas de alecrim (Rosmarinus officinalis L.) e espinheira-santa (Maytenus ilicifolia Mart.) contra as bactérias bucais. Materiais e método: as bactérias utilizadas no estudo foram Streptococcus mutans (ATCC 25175), Streptococcus oralis (ATCC 10557), Streptococcus salivarius (ATCC 9758), Enterococcus faecalis (ATCC 29212) e Eikenella corrodens (ATCC 23834). Efetivou-se a diluição das tinturas desde 1:1 (forma pura) até 1:64 em álcool 70\%, que está presente na fórmula das tinturas fitoterápicas. Água destilada e álcool $70 \%$ foram escolhidos como controles negativos, e clorexidina $0,12 \%$ como o positivo. As cepas foram reativadas em ágar Brain Heart Infusion (BHI) e semeadas em ágar sangue com BHI. Os testes de sensibilidade foram realizados e as amostras foram incubadas em microaerofilia $\left(37^{\circ} \mathrm{C}\right)$ durante 48 horas. O estudo foi realizado em duplicata e os halos foram mensurados com o auxílio de um paquímetro manual e contabilizados por média. Resultados: o controle positivo apresentou halos que variaram de $15 \mathrm{~mm}$ a $19 \mathrm{~mm}$, a tintura de Maytenus ilicifolia não apresentou atividade antibacteriana nos organismos testados neste estudo, e a tintura de Rosmarinus officinalis L. obteve halos de inibição até 1:16 em $S$. mutans $(7 \mathrm{~mm})$ e 1:8 para E. faecalis $(7 \mathrm{~mm})$. Conclusão: a tintura de alecrim apresentou atividade antibacteriana para as cepas de Streptococcus mutans e Enterococcus faecalis, não foi constatado esse efeito para a tintura de espinheira-santa sobre as linhagens testadas no estudo.

Palavras-chave: Microbiologia. Fitoterapia. Antibacteriano.

\section{Introdução}

Nas últimas décadas, o interesse pela fitoterapia aumentou consideravelmente entre usuários, pesquisadores e serviços de saúde ${ }^{1}$. $\mathrm{O}$ processo de reconhecimento científico mundial da utilização de medicamentos fitoterápicos é antigo, e desde a Declaração de Alma-Ata, em 1978, tem expressado a sua posição a respeito da necessidade de valorizar a utilização de plantas medicinais no âmbito sanitário e na atenção básica à saúde ${ }^{2}$. Nessa declaração, a Organização Mundial da Saúde reconhece que $80 \%$ da população dos países em desenvolvimento utilizam práticas tradicionais nos seus cuidados básicos de saúde, e $85 \%$ usam plantas medicinais ou preparações dessas ${ }^{1}$.

Portanto, trabalhos que visem à utilização de fitofármacos ou produtos medicinais à base de partes de plantas merecem destaque no âmbito social e científico, pela potencialidade de subsidiar tratamentos de diferentes agravos existentes nas mais diversas áreas da saúde. Avaliar a atividade antimicrobiana surge como teste para verificar a hipótese de ação de produtos fitoterápicos para a realização de testes posteriores mais específicos e precisos ${ }^{3}$.

Nessa perspectiva, o alecrim, Rosmarinus officinalis L., pertencente à família Lamiaceæ, é nativo da região mediterrânea, embora cresça em diversos tipos de solos, em regiões de até 2.800 metros de altitude. Trata-se de um arbusto aromático, perene,

\footnotetext{
Mestrado em Odontologia, área de concentração em Odontopediatria, Universidade Federal do Rio de Janeiro, RJ, Brasil.

Doutora em Modelos de Decisão e Saúde, Universidade Federal da Paraíba, PB, Brasil.

* Graduando(a) em Odontologia, Universidade Federal da Paraíba, PB, Brasil.

${ }^{* * *}$ Doutora, professora titular, Universidade Federal da Paraíba, PB, Brasil.
} 
que atinge até 1 metro de altura, com caule lenhoso, folhas simples, opostas, lineares e de até $3,5 \mathrm{~cm}$. Popularmente chamado de alecrim (português), romero (espanhol), rosemary (inglês), romarim (francês) ou rosmarino (italiano) ${ }^{4}$, é uma planta utilizada desde os tempos antigos para fins medicinais por sua reconhecida ação antisséptica ${ }^{5}$, antirreumáti$\mathrm{ca}^{6}$, anti-inflamatória e suas propriedades antiespasmódicas ${ }^{7}$.

Extratos e tinturas de Rosmarinus officinalis L. apresentam ainda propriedades importantes, como ação de proteção hepática ${ }^{8}$, antidiabética ${ }^{9}$, antiulcerosa $^{10}$ e efeitos antidepressivos ${ }^{11}$. Estudos detalhados sobre a sua composição afirmam que os principais compostos antioxidantes identificados são ácido carnósico, carnosol, abietanos diterpenos, ácido rosmarínico e éster ácido hidroxicinâmico ${ }^{12}$. É relatado que essa planta tem grande quantidade de compostos fenólicos e elevada atividade antimicrobiana contra bactérias Gram-positivas e Gram-negativas, devido à ação do ácido carnósico e do carnosol ${ }^{13}$. No entanto, as atividades antimicrobianas não foram profundamente caracterizadas e mensuradas ${ }^{14}$.

Maytenus ilicifolia Mart. é pertencente à Celastraceæ, uma família pantropical nativa da região sul do Brasil, Paraguai, Uruguai e norte da Argentina. A planta é um pequeno arbusto medicinal que cresce a uma altura de até 5 metros, com folhas e frutos que se assemelham aos do azevinho. É popularmente conhecida como espinheira-santa (holy spine), cancerosa, cangorosa, maiteno e espinheira divina (divine spine) ${ }^{15}$.

A espinheira-santa é amplamente empregada na medicina tradicional em muitos países da América do Sul, suas folhas são comumente utilizadas como remédio para doenças gastrointestinais, incluindo dispepsia e úlceras gástricas ${ }^{16}$. Remédios com essa planta são encontrados no comércio local, com apresentação em cápsulas, pós, folhas secas, ou como preparações aquosas ou aquoso-alcoólicas. Ao analisar a composição química, a comprovada presença de metabólitos fenólicos, tais como taninos condensados, flavonoides e triterpenos ${ }^{16}$, poderia justificar o uso de algumas espécies de Maytenus como medicamento anti-inflamatório e no combate a úlceras. Essas funções são corroboradas cientificamente e abrem espaço para a utilização dessa tintura para esses agravos. Quanto à atividade antiulcerogênica, destaca-se a ação de proteção semelhante à observada com a cimetidina, um reconhecido antagonista do receptor da histamina ${ }^{16}$.

Portanto, devido às importantes atividades promovidas pelas plantas alecrim (Rosmarinus officinalis L.) e espinheira-santa (Maytenus ilicifolia Mart.), este estudo justifica-se por complementar a literatura científica atual ao testar a ação dessas plantas sobre bactérias orais de diferentes grupos nos quais a atividade antibacteriana é pouco ou não é relatada. Nessa perspectiva, objetivou-se ava- liar a atividade inibitória em bactérias in vitro das tinturas de alecrim (Rosmarinus officinalis L.) e espinheira-santa (Maytenus ilicifolia Mart.) contra as cepas comumente encontradas em meio bucal, Streptococcus mutans (ATCC 25175), Streptococcus oralis (ATCC 0557), Streptococcus salivarius (ATCC 9758), Enterococcus faecalis (ATCC 29212) e Eikenella corrodens (ATCC 23834).

\section{Materiais e método}

Trata-se de um estudo com técnica de documentação direta laboratorial e com procedimento estatístico descritivo.

As tinturas hidroalcoólicas de alecrim (Rosmarinus officinalis L.) e espinheira-santa (Maytenus ilicifolia Mart.) foram adquiridas em uma farmácia de manipulação fitoterápica na cidade de João Pessoa, PB. Ao analisar o laudo técnico, verificou-se que as formulações se encontram comercialmente com uma diluição prévia industrial de $20 \%$ em álcool 70\%. Tal concentração, incialmente já diluída em $20 \%$, foi adotada como a concentração pura neste estudo. Portanto, para evitar possíveis vieses nos resultados, optou-se por adotar o álcool $70 \%$ como um dos controles negativos do estudo. Efetivou-se a diluição das tinturas desde 1:1 (forma pura) até 1:64 (D6 - sexta diluição) em álcool 70\%, por estar presente na formulação prévia das tinturas fitoterápicas.

Outro controle negativo utilizado foi a água destilada, que é comprovadamente ineficaz no combate químico às bactérias. Como controle positivo foi utilizado o digluconato de clorexidina $0,12 \%$ sem álcool $\left(\right.$ Periogard $\left.^{\circledR}\right)$, por ter uma concentração ótima para a cavidade bucal.

Para a etapa microbiológica, foram utilizadas cepas de Streptococcus mutans (ATCC 25175), Streptococcus oralis (ATCC 10557), Streptococcus salivarius (ATCC 9758), Enterococcus faecalis (ATCC 29212) e Eikenella corrodens (ATCC 23834), que foram reativadas em BHI caldo - Brain Heart Infusion (DIFCO ${ }^{\circledR}$, São Paulo, SP, Brasil). Os micro-organismos foram obtidos do Laboratório de Materiais de Referência do Instituto Nacional de Controle de Qualidade em Saúde (Fundação Oswaldo Cruz, Rio de Janeiro, RJ, Brasil) e disponibilizados pelo Laboratório de Microbiologia Oral, localizado no Núcleo de Medicina Tropical do Centro de Ciências da Saúde da Universidade Federal da Paraíba, João Pessoa, PB, Brasil.

A escala 0,5 de McFarland (1,5 x $10^{8}$ micro-organismos/mL) foi adotada para a preparação dos inóculos, que foram diluídos até atingir a concentração de $5 \times 10^{6}$ micro-organismos $/ \mathrm{mL}$. A semeadura de $50 \mu \mathrm{l}$ dos micro-organismos foi realizada homogeneamente em cada placa de Petri com auxílio de swabs descartáveis. O teste de susceptibilidade foi realizado utilizando o método de difusão em ágar e 
as placas com inóculo foram incubadas a $37^{\circ} \mathrm{C}$, em microaerofilia, por 48 horas.

Para a difusão em ágar, foram realizados poços com ponteiras estéreis e inserido em cada $50 \mu \mathrm{lda}$ substância teste. O estudo foi realizado em duplicata e os halos de inibição foram mensurados com o auxílio de um paquímetro manual. Os escores finais foram obtidos pela média do diâmetro (em milímetros) dos halos de inibição de crescimento bacteriano e os dados foram analisados descritivamente.

\section{Resultados}

Rosmarinus officinalis $\mathrm{L}$. foi a única planta que promoveu atividade antibacteriana sobre as cepas de Streptococcus mutans e Eikenella corrodens, com halos de inibição até a concentração de $14,0625 \mathrm{mg} /$
$\mathrm{mL}$ (7 mm). Em S. salivarius e E. faecalis, foi encontrada ação antimicrobiana semelhante, com formação de halos médios de $7 \mathrm{~mm}$ de diâmetro na concentração de $14,0625 \mathrm{mg} / \mathrm{mL}$. Em $S$. oralis, a ação realizada ocorreu até a diluição de 1:8 $(112,5 \mathrm{mg} /$ $\mathrm{mL}$ ), com uma média de halos de inibição de $7 \mathrm{~mm}$.

Os controles negativos (álcool $70 \%$ e água destilada) não influenciaram no crescimento bacteriano, e o controle positivo apresentou os maiores halos de inibição, destacando-se halos de $19 \mathrm{~mm}$ para Streptococcus oralis (Tabela 1).

Maytenus ilicifolia Mart. obteve uma atividade mais discreta e destacou-se por impedir o crescimento bacteriano até a concentração de $112,5 \mathrm{mg} /$ $\mathrm{mL}$, com um halo médio de $7,5 \mathrm{~mm}$ para $E$. faecalis. Para S. oralis e salivarius, a atividade encontrada ocorreu até $225 \mathrm{mg} / \mathrm{mL}$, promovendo a formação de halos médios de $7 \mathrm{~mm}$ de diâmetro.

Tabela 1 - Média dos halos de inibição do crescimento (em milímetros) das tinturas fitoterápicas das folhas do alecrim e da espinheira-santa e dos controles frente às cepas bacterianas testadas

\begin{tabular}{|c|c|c|c|c|c|c|c|c|c|c|}
\hline & \multicolumn{10}{|c|}{ Halos de inibição (mm) } \\
\hline & CN1 & $\mathrm{CN} 2$ & C P & $\begin{array}{c}900 \mathrm{mg} / \mathrm{mL} \\
(1: 1)\end{array}$ & $\begin{array}{c}450 \\
\mathrm{mg} / \mathrm{mL} \\
(1: 2)\end{array}$ & $\begin{array}{c}225 \\
\mathrm{mg} / \mathrm{mL} \\
(1: 4)\end{array}$ & $\begin{array}{c}112,5 \\
\mathrm{mg} / \mathrm{mL} \\
(1: 8)\end{array}$ & $\begin{array}{c}56,25 \\
\mathrm{mg} / \mathrm{mL} \\
(1: 16)\end{array}$ & $\begin{array}{c}28,125 \\
\mathrm{mg} / \mathrm{mL} \\
(1: 32)\end{array}$ & $\begin{array}{c}14,0625 \\
\mathrm{mg} / \mathrm{mL} \\
(1: 64)\end{array}$ \\
\hline \multicolumn{11}{|c|}{ Tintura de Rosmarinus officinalis L. (alecrim) } \\
\hline S. mutans & 0 & 0 & 16 & 9 & 8,5 & 8 & 8 & 7,5 & 7 & 7 \\
\hline S. oralis & 0 & 0 & 16 & 8 & 7,5 & 7 & 7 & 0 & 0 & 0 \\
\hline S. salivarius & 0 & 0 & 13 & 9,5 & 9 & 8,5 & 8 & 8 & 7,5 & 7 \\
\hline E. faecalis & 0 & 0 & 15 & 9 & 8,5 & 8,5 & 8 & 7,5 & 7,5 & 7 \\
\hline E. corrodens & 0 & 0 & 14 & 7,5 & 7,5 & 7,5 & 7,3 & 7,1 & 7 & 7 \\
\hline \multicolumn{11}{|c|}{ Tintura de Maytenus ilicifolia Mart. (espinheira-santa) } \\
\hline S. mutans & 0 & 0 & 16 & 0 & 0 & 0 & 0 & 0 & 0 & 0 \\
\hline S. oralis & 0 & 0 & 16 & 9 & 7 & 0 & 0 & 0 & 0 & 0 \\
\hline S. salivarius & 0 & 0 & 13 & 7 & 7 & 0 & 0 & 0 & 0 & 0 \\
\hline E. faecalis & 0 & 0 & 15 & 9 & 8,5 & 8 & 7,5 & 0 & 0 & 0 \\
\hline E. corrodens & 0 & 0 & 14 & 0 & 0 & 0 & 0 & 0 & 0 & 0 \\
\hline
\end{tabular}

Fonte: elaboração dos autores com base nos dados da pesquisa.

Nota: $\mathrm{CN} 1$ = controle negativo 1: água destilada; CN2 = controle negativo 2: álcool 70\%; CP = controle positivo: digluconato de clorexidina 0,12\% sem álcool; 1:X grau de diluição da tintura em álcool $70 \%$.

\section{Discussão}

Os testes com agentes antimicrobianos sobre bactérias orais planctônicas podem qualificar 0 agente para tratamento de infecções orais biofilme-dependentes ou desqualificá-lo, caso esses testes demonstrem resultados negativos ${ }^{17}$. Assim, este estudo foi desenvolvido em razão dos poucos estudos existentes na literatura que avaliam a ação antibacteriana das tinturas hidroalcoólicas de Rosmarinus officinalis e de Maytenus ilicifolia sobre bactérias bucais.

Para as análises, foi empregado o álcool $70 \%$ como controle negativo devido à substância estar presente na composição das tinturas hidroalcoólicas. É importante destacar que, devido à resistên- cia bacteriana ao álcool, o efeito antimicrobiano das tinturas analisadas no presente estudo não foi influenciado pelo veículo utilizado na sua fabricação. Essa constatação decorre da ausência de atividade bacteriana do álcool $70 \%$, que é corroborada em estudo anterior ${ }^{3}$. A atividade encontrada com a tintura de Rosmarinus officinalis L. é considerada reduzida, pois apresentou diâmetro máximo dos halos de inibição de apenas $9 \mathrm{~mm}, 8 \mathrm{~mm}$ em sua forma pura (1:1), e ação até 1:16 e 1:8 (ambos com $7 \mathrm{~mm}$ ) para Streptococcus mutans e Enterococcus faecalis, respectivamente. Considerando o desenho metodológico do estudo, constatou-se que a ação antibacteriana da tintura mostrou-se inferior à registrada para o digluconato de clorexidina $0,12 \%$ (que atingiu diâmetros máximos de 19 
mm em sua forma pura comercial). Esses achados apontam que a tintura de Rosmarinus officinalis apresenta fraca atividade bacteriana sobre as cepas em teste.

Os resultados dos estudos laboratoriais podem não refletir o efeito real de um material quando aplicado em uma condição in vivo ${ }^{18}$. Portanto, os dados obtidos não devem ser extrapolados para uma situação clínica por vários motivos, como diluição do composto em saliva, $\mathrm{pH}$ bucal, temperatura, além do fato de que o estudo abrange bactérias isoladamente, diferentemente da condição bucal em que o biofilme apresenta cadeia complexa de micro-organismos. Com base nos resultados obtidos, que comprovam a fraca atividade da tintura de Maytenus ilicifolia, estudos complementares e ensaios clínicos com esse produto mostram-se pouco promissores. Todavia, ressalta-se que a parte utilizada para a tintura é a folha, sendo, portanto, arriscado afirmar que toda a planta não apresenta atividade antibacteriana contra as bactérias estudadas.

Além disso, óleos essenciais, extratos e tinturas de alecrim apresentam elevada diferença em suas atividades antimicrobiana e antioxidante. Essas disparidades são associadas com a composição química e com as variações da própria espécie ${ }^{13}$.

Certos fatores, como local de origem ${ }^{19}$, ambiente e condições agronômicas ${ }^{20}$, período da colheita ${ }^{21}$, estágio de desenvolvimento das plantas ${ }^{22}$ e método de extração $0^{23}$, influenciam a eficácia dessas propriedades e podem explicar a reduzida atividade antibacteriana da tintura de Rosmarinus officinalis L. e da ausência de atividade de Maytenus ilicifolia Mart.

Em estudo que avaliou os quimiotipos da Rosmarinus officinalis L., a atividade antibacteriana foi evidente contra bactérias encontradas comumente em alimentos e que podem ocasionar infecções e problemas enterais, como Staphylococcus aureus, Escherichia coli, Salmonella typhimurium e Listeria monocytogenes ${ }^{24}$. Este estudo ainda indica que o quimiotipo, que é uma variação biológica de uma planta ocasionada por fatores externos, como luz solar, calor, temperatura ou condições meteorológicas, é determinante para a atividade antibacteriana, existindo a necessidade de definir e isolar que quimiotipo ou ordem de abundância dos componentes ativos seriam responsáveis pela obtenção de melhores escores de atividade antimicrobiana.

Há ainda evidência de atividade antibacteriana do alecrim contra o Staphylococcus epidermidis, Bacillus subtilis, Proteus vulgaris, Pseudomonas aeruginosa $^{25}$ e espécies de Listeria (ivanovii, monocytogenes, grayi, innocua e monocytogenes, essa em oito subtipos) ${ }^{14}$, além dessas, há ação antifúngica em Candida albicans e Aspergillus niger ${ }^{25}$. Em estudo anterior, avaliou-se uma possível atividade diante de outras importantes bactérias do biofilme oral: Streptococcus mutans, Lactobaccilus casei (ação até
1:4 com $11 \mathrm{~mm}$ ), S. sanguinis, $S$. sobrinus (halos de $15 \mathrm{~mm}$, para ambas, apenas na solução $1: 1$ ) e $S$. $m i$ tis (sem ação inibitória) ${ }^{26}$. O atual estudo demostrou maior efetividade residual diante de $S$. mutans, pois o alecrim expressou ação até 1:16 $(7 \mathrm{~mm})$.

Este estudo também avaliou a ação contra outras importantes bactérias do biofilme dentário: Streptococcus sanguinis, S. mitis, S. sobrinus e Lactobaccilus casei (ação apenas na última, 1:1 com 17 $\mathrm{mm}$, até 1:4 com $11 \mathrm{~mm})^{26}$.

Escassos são os estudos científicos na literatura que abordam a atividade antibacteriana da tintura de Maytenus ilicifolia sobre bactérias presentes na cavidade oral. Em adição, diferentes são as metodologias laboratoriais utilizadas, o que dificulta a comparação entre os resultados obtidos, indicando a necessidade de estudos posteriores que comprovem ou refutem os achados registrados no presente trabalho. Em estudo realizado com Streptococcus mutans, S. oralis, S. mitis e Staphylococcus aureus, coletadas de cães e semeadas em meios de cultura, foi encontrada ação antimicrobiana. No entanto, devido às consideráveis diferenças entre bactérias orais da mesma espécie presentes em cães e em humanos, torna-se temerária a comparação com os resultados encontrados neste estudo ${ }^{27}$.

Em complementação, resultados distintos, embora incomuns, podem ocorrer devido a interferências externas que podem incidir sobre as plantas, como a região geográfica de origem e o processo de formulação das tinturas e estocagem. Contudo, essas condições não comprometem o estudo, pois os fatores anteriormente elencados não são passíveis de controle, optando-se, no presente estudo, pela utilização de uma formulação pronta, acompanhada do respectivo laudo técnico.

Diante do exposto, embora estudos in vitro sofram críticas por apresentarem resultados potencialmente superestimados devido às condições ideais de crescimento bacteriano e de ação da substância a ser testada (não há influência de fatores externos como $\mathrm{pH}$, saliva, temperaturas instáveis, dentre outras características presentes na cavidade oral), eles orientam o desenvolvimento de posteriores estudos clínicos contribuindo para a definição de quais substâncias, compostos ou formulações apresentam potencial ação antibacteriana.

\section{Conclusão}

A tintura fitoterápica de alecrim (Rosmarinus officinalis L.) apresentou fraca atividade antibacteriana em amostras de Streptococcus mutans e Enterococcus faecalis, não sendo constatado esse efeito para a tintura de espinheira-santa (Maytenus ilicifolia) sobre as linhagens testadas no estudo. 


\section{Abstract}

Objective: To assess in vitro antibacterial activity of hydroalcoholic tinctures from leaves of rosemary (Rosmarinus officinalis L.) and espinheira-santa (Maytenus ilicifolia Mart.) on oral bacteria. Materials and Method: Streptococcus mutans (ATCC 25175), Streptococcus oralis (ATCC 10557), Streptococcus salivarius (ATCC 9758), Enterococcus faecalis (ATCC 29212), and Eikenella corrodens (ATCC 23834) were the bacterial strains used in this study. The dilution of tinctures was performed, from 1:1 (pure form) up to 1:64 in 70\% alcohol, which is present in the formula of phytotherapeutic tinctures. Distilled water and $70 \%$ alcohol were selected as negative controls, and $0.12 \%$ chlorhexidine as positive control. The strains were reactivated in Brain Heart Infusion (BHI) agar and sowed in blood agar with BHI. Susceptibility tests were performed and samples were incubated in microaerophilia $\left(37^{\circ} \mathrm{C}\right)$ for $48 \mathrm{~h}$. The study was performed in duplicate, the halos were measured with the aid of a manual caliper, and scores were recorded as mean. Results: The positive control showed inhibition halos ranging from 15 to 19 $\mathrm{mm}$, the Maytenus ilicifolia tincture did not show antibacterial activity on the organisms tested in this study, and the Rosmarinus officinalis L. tincture obtained inhibition halos of up to 1:16 in S. mutans $(7 \mathrm{~mm})$ and 1:8 in E. faecalis ( $7 \mathrm{~mm})$. Conclusion: Rosemary tincture showed antibacterial activity on Streptococcus mutans and Enterococcus faecalis strains, although the same was not true for espinheira-santa tincture on the strains tested in the study.

Keywords: Microbiology. Phytotherapy. Anti-Bacterial Agent.

\section{Referências}

1. World Health Organization (WHO). Legal status of traditional medicine and complementary/alternative medicine. Geneva: World Health Organization; 2001.

2. World Health Organization (WHO). WHO Strategy for Traditional Medicine 2002-2005. Geneva: World Health Organization; 2002.

3. Ferreira-Filho JCC, Gondim BLC, Cunha DA, Figueiredo $\mathrm{CC}$, Valença AMG. Physical properties and antibacterial activity of herbal tinctures of Calendula (Calendula officinalis L.) and Cashew Tree (Anacardium occidentale L.). Pesqui Bras Odontopediatria Clin Integr 2014; 14(1):49-53.

4. Alonso JR. Tratado de fitomedicina - bases clínicas e farmacológicas. Buenos Aires: Isis; 1998. 1.039 p.

5. Rampart M, Beetens JR, Bult H, Herman AG, Parnham MJ, Winkelmann J. Complement dependent stimulation of prostacyclin biosynthesis: inhibition by rosmarinic acid. Biochem Pharmacol 1986; 35(8):1397-400.

6. Makino T, Ono T, Muso E, Yoshida H, Honda G, Sasayama S. Inhibitory effects of rosmarinic acid on the proliferation of cultured murine mesangial cells. Nephrol Dial Transplant 2000; 15(8):1140-5.

7. Benincá JP, Dalmarco JB, Pizzolatti MG, Fröde TS. Analysis of the anti-inflammatory properties of Rosmarinus officinalis L. Food Chem 2011; 124(2):468-75.
8. Amin A, Hamza AA. Hepatoprotective effects of Hibiscus, Rosmarinus and Salvia on azathioprine-induced toxicity in rats. Life Sci 2005; 77(3):266-78.

9. Abu-Al-Basal MA. Healing potential of Rosmarinus officinalis L. on full-thickness excision cutaneous wounds in alloxan-induced-diabetic. J Ethnopharmacol 2010; 131(2):44350 .

10. Dias PC, Foglio MA, Possenti A, Carvalho JE. Antiulcerogenic activity of crude hydroalcoholic extracts of Rosmarinus officinalis L. J Ethnopharmacol 2000; 69(1):57-62.

11. Machado GD, Bettio LEB, Cunha MP, Capra JC, Dalmarco JB, Pizzolatti MG et al. Antidepressant-like effect of the extract of Rosmarinus officinalis. Prog Neuropsychopharmacol Biol Psychiat 2009; 33(4):642-50.

12. Del Bano MJ, Lorente J, Castillo J, Benavente-Garcia O, Rio JA, Otuno A et al. Phenolic diterpenes, flavones, and rosmarinic acid distribution during the development of leaves, flowers, stems, and roots of Rosmarinus officinalis and antioxidant activity. J Agric Food Chem 2003; 51(15):4247-53

13. Moreno S, Scheyer T, Romano CS, Vojnov AA. Antioxidant and antimicrobial activities of Rosemary extracts linked to their polyphenol composition. Free Radic Res 2006; 40(2):223-31.

14. Rozman T, Jersek B. Antimicrobial activity of rosemary extracts (Rosmarinus officinalis L.) against different species of Listeria. Acta Agric Slov 2009; 93(1):51-8.

15. Cordeiro DS, Raghavan GSV, Oliveira WP. Equilibrium moisture content models for Maytenus ilicifolia leaves. Biosyst Eng 2006; 94(2):221-8.

16. Leite JPV, Braga FC, Romussi G, Persoli RM, Tabach R, Carlinid EA et al. Constituents from Maytenus ilicifolia leaves and bioguided fractionation for gastroprotective activity. J Braz Chem Soc 2010; 21 (2):248-54.

17. Costerton JW, Cheng KJ, Geesey GG, Ladd TI, Nickel JC, Dasgupta $\mathrm{M}$ et al. Bacterial biofilms in nature and disease. Ann Rev Microbiol 1987; 41:435-64.

18. Souza-Gugelmin MCM, Silva FWGP, Queiroz AM, Amaral THA. Avaliação da atividade antimicrobiana de dentifrícios infantis: estudo in vitro. Rev Fac Odontol Porto Alegre 2006; 47(3):10-3.

19. Jamshidi R, Afzal Z, Afzali D. Chemical composition of hydrodistillation essential oil of rosemary in different origins in Iran and comparison with other countries. AmericanEurasian J Agric Environ Sci 2009; 5(1):78-81.

20. Moghtader M, Afzali D. Study of the antibacterial properties of the essential oil of rosemary. American-Eurasian J Agric Environ Sci 2009; 5(3):393-7.

21. Celiktas OY, Hames Kocabas EE, Bedir E, Vardar Sukan F, Ozek T, Baser KHC. Antimicrobial activities of methanol extracts and essential oils of Rosmarinus officinalis, depending on location and seasonal variations. Food Chem 2007; 100 (2):553-9.

22. Ruberto G, Barata MT. Antioxidant activity of selected essential oil components in two lipid model system. Food Chem 2000; 69(2):167-74. DOI:10.1016/S0308-8146(99)00247-2.

23. Okoh OO, Sadimenko AP, Afolayan AJ. Comparative evaluation of the antibacterial activities of the essential oils of Rosmarinus officinalis L. obtained by hydrodistillation and solvent free microwave extraction methods. Food Chem 2010; 120(1):308-12

24. Jordán MJ, Lax V, Rota MC, Lorán S, Sotomayor JA. Effect of bioclimatic area on the essential oil composition and antibacterial activity of Rosmarinus officinalis L. Food Control 2013; 30(2):463-8. 
25. Jiang Y, Wu N, Fu YJ, Wang W, Luo M, Zhao C et al. Chemical composition and antimicrobial activity of the essential oil of rosemary. Environ Toxicol Pharmacol 2011; 3(2):63-8.

26. Silva MSA, Silva MAR, Higino JS, Pereira MSV, Carvalho AAT. Atividade antimicrobiana e antiaderente in vitro do extrato de Rosmarinus officinalis Linn. sobre bactérias orais planctônicas. Rev Bras Farmacogn 2008; 18(2):236-40.

27. Menezes MC, Souza MMS, Botelho RP. Avaliação in vitro da atividade antimicrobiana de extratos de plantas brasileiras sobre bactérias isoladas da cavidade oral de cães. Rev Univ Rural 2004; 24(2):141-4.

\section{Endereço para correspondência:}

Julio Cesar Campos Ferreira Filho

Rua Lindolfo Gonçalves Chaves, 65,

Ed. Diadema, apto. 101, Jardim São Paulo

58051-200 João Pessoa, PB, Brasil

Telefone: (083) 9654-2580

E-mail jcesarodonto@live.com

Recebido: 16/09/15. Aceito: 04/01/16. 